\title{
Patient-Provider Racial and Ethnic Concordance and Parent Reports of the Primary Care Experiences of Children
}

Gregory D. Stevens, $P b D^{1}$

Leiyu Shi, DrPH, MPA, MBA ${ }^{2}$

Lisa A. Cooper, $M D, M P H^{2,3}$

${ }^{1}$ Center for Healthier Children, Families and Communities, University of California, Los Angeles, Calif ment, Johns Hopkins University Bloomberg School of Public Health, Baltimore, Md

${ }^{3}$ Department of Medicine, Johns Hopkins University School of Medicine, Baltimore, Md

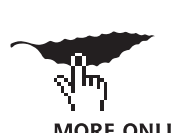

MORE ONLINE
www.annfammed.org
${ }^{2}$ Department of Health Policy and Manage-

\begin{abstract}
PURPOSE Studies among adults suggest that patient-provider racial concordance is associated with higher satisfaction and partnership with physicians. It remains unknown whether similar findings are true for children. This study examines the association of race/ethnicity concordance with parent reports of children's primary care experiences.

METHODS We completed telephone interviews with a random, cross-sectional sample of 413 parents of elementary school children, aged 5 to 12 years, enrolled in a single large school district serving 3 cities in San Bernardino, Calif. Parents reported on their children's primary care experiences, and the responses were compared between children in race concordant and discordant patientprovider relationships.
\end{abstract}

RESULTS We assessed parent reports of 6 structure and process features of primary care: first-contact care (accessibility, utilization), longitudinality (strength of affiliation, interpersonal relationship), and comprehensiveness (services offered, received). Before and after controlling for demographics, socioeconomic status, and health system factors, race/ethnicity concordance was not associated with children's primary care experiences. Minority parents generally reported poorer experiences than whites in several domains of primary care, but the only significant effect of race/ethnicity concordance was slightly better primary care utilization for whites in concordant relationships, which did not hold after adjustment.

CONCLUSION In contrast with studies among adults, patient-provider race/ethnicity concordance was not associated with parent reports of primary care experiences in our sample of children. It is possible that provider biases or patient expectations that contribute to disparities in care for adults are attenuated in relationships involving children.

Ann Fam Med 2003;1:105-112. DOI: 10.1370/afm.27.

\section{INTRODUCTION}

Conflicts of interest: none reported

\section{CORRESPONDING ADDRESS}

Gregory D. Stevens, PhD

Center for Healthier Children, Families and Communities

University of California, Los Angeles 10945 LeConte Ave, Ste 1401 Los Angeles, CA 90095-6939 gregory@ucla.edu lthough racial and ethnic disparities in children's primary care expe-
riences have been documented in the literature, ${ }^{1-8}$ differences in
socioeconomic status, insurance coverage, and language contribute to, but do not completely explain, these disparities in health care. A recent report by the Institute of Medicine describing racial gaps in the delivery of health care suggests that, in addition to these factors, components of the patient-provider relationship might also be contributing factors. ${ }^{9}$

Patient-provider relationship factors, such as interpersonal communication, trust, and mutual understanding of cultural differences in health needs and expectations might, in fact, be affected by the race and eth- 
nicity of both patients and providers. A recent study of disparities in quality of care suggests that minority patients are frequently dissatisfied with their interactions with physicians and report difficulties communicating effectively because of language or cultural issues. ${ }^{10}$ Several studies have shown that race/ethnicity concordance is positively associated with aspects of care for adults, such as participatory decision making, interpersonal respect, and satisfaction. ${ }^{11-14}$

The effect of race/ethnicity concordance on the delivery of primary care has not yet been studied for children despite vast differences in the health needs of and delivery systems designed for children and adults. ${ }^{15}$ Most studies of disparity in primary health care have focused on the technical aspects of care delivery, such as the receipt of tests, procedures, and therapies, rather than experiences in primary care. The purpose of this study was to explore the association between patient-provider race/ethnicity concordance and parent-reported primary care experiences of children and to determine whether having a race or ethnicity concordant relationship would contribute to reducing known disparities in primary care.

\section{METHODS}

\section{Study Design and Setting}

We conducted a cross-sectional, community-based survey of the parents of a sample of 1,200 elementary school children in 1 school district. The district serves 3 large cities in San Bernardino County, Calif. The sampling frame of children (aged 5 to 12 years) was sorted by sex, grade, and school stratum, and systematically sampled (ie, selecting every Xth child) to ensure that the sample was as representative of the community as possible. Because of the few Asian and African American children, these subgroups were oversampled at 4 and 16 -times the rate of whites to obtain roughly equal numbers of respondents across racial and ethnic groups and improve our analytic capacity.

\section{Data Collection}

The Johns Hopkins University Office for Research Subjects, Baltimore, Md, approved the survey instrument and administration procedures. Questionnaires were administered through structured telephone interviews in January 2001. Spanish-speaking interviewers and questionnaires were made available to parents, but only 7 parents requested interviews in Spanish. Data on child race-ethnicity, sex, grade level, and school were available in an administrative data set assembled annually by the school district from parent-completed school enrollment forms.

\section{Measurement of Study Variables}

Race and Ethnicity. Categories of child race and ethnicity coded from parent self-report were white, Latino, African American, Asian, Filipino, Pacific Islander, and Native American. We combined Asian, Filipino, and Pacific Islander into a single category called Asian and Pacific Islander, and we chose to exclude the few Native Americans from the study sample. Children of multiple race or ethnicity (less than $1 \%$ of the school district population) were also excluded from the original sampling frame because of difficulty coding their race-ethnicity for analytic purposes.

Race and Ethnicity Concordance. The independent variable was race/ethnicity concordance between child and provider. Respondents who indicated a regular provider for their child were asked to report the racial-ethnic background of that provider. Response categories included white, African American, Latino, Asian and Pacific Islander, and other. If the background of the child and provider matched, it was coded as a concordant relationship. If the background did not match, or if a respondent reported "other" provider race and ethnicity, it was coded as a discordant relationship. If a parent did not know the racial or ethnic background of the provider, we coded the relationship as discordant, assuming that parents would be able to recognize a provider of the same background, at least at a general level. ${ }^{16}$ Excluding respondents who did not know the race or ethnicity of their regular provider had no effect on the results and were kept in the analysis.

Primary Care Experience. The Institute of Medicine defines primary care as "the provision of integrated, accessible health care services by clinicians who are accountable for addressing a large majority of personal health care needs, developing a sustained partnership with patients, and practicing in the context of family and community." ${ }^{17}$ The definition comprises 4 attributes of primary care: (1) first-contact care with a designated provider $_{i}(2)$ longitudinality, or ongoing care, with a provider or place of care ${ }_{i}(3)$ comprehensiveness of services; and (4) coordination of those services. ${ }^{18}$

We used the Pediatric Primary Care Assessment Tool-Child Edition (PCAT-CE) developed by the Johns Hopkins Primary Care Policy Center for the Underserved to assess primary care experiences. ${ }^{19}$ The PCAT-CE uses parent reports because children are generally dependent on adults for most of their health care, and because parents are best positioned to report on factors such as accessibility, utilization, and comprehensiveness of services. Although children might effectively rate interpersonal factors, no instrument has been developed to assess such primary care experiences from the child's perspective. 
Whereas other instruments that evaluate primary care focus mainly on subjective satisfaction ratings, the PCAT asks parents to report on more objective experiences with care. Satisfaction ratings are evaluated against the expectations of the respondent, which vary widely across individuals. ${ }^{20,21}$ Reports of experiences are measured against prescriptive criteria (eg, that a child should be seen the same day for a health problem), so that deviations from the criteria represent potential gaps in quality.

Scale scores were created for each attribute based on summed responses to the questions with Likerttype response choices: definitely $=4$, probably $=3$, probably not $=2$, and definitely not $=1$. "Don't know" responses were coded as the middle score (2.5),

because not knowing about an aspect of primary care signifies some partial failure of the provider to convey that feature of care. For ease of interpretation, primary care domain and total primary care scores were converted to a 100-point scale. The survey items along with the reliability and validity of the instrument are reported elsewhere. ${ }^{22} 23$

First-Contact Care. Two domains of first-contact care are measured by the PCAT: (1) accessibility of the provider and (2) utilization, or the degree to which the provider is used as a single point of entry into medical care. Accessibility measures aspects of the health system that facilitate access, such as whether the provider would usually be able to see the child the same day. Utilization assigns a higher score for each service (acute care, regular check-up, and immunizations) than is sought from the provider.

Longitudinality. Two domains of longitudinality are measured by the PCAT: (1) the interpersonal relationship and (2) the strength of affiliation with the provider. The relationship domain measures the whole-person focus of patient-provider interactions (eg, the focus on the whole child, not just the medical problem). Affiliation assigns a higher score if the regular provider also knows the child best and is the source of care for new health problems.

Comprehensiveness. Two domains of comprehensiveness are measured by the PCAT: (1) services available and (2) services provided. Six questions address availability of specific primary care services (eg, immunizations and tests for lead poisoning). Five questions address the services received from the provider (eg, discussions of ways to stay healthy, such as eating nutritious foods and getting enough sleep).

Total Score. To summarize the overall primary care experience, a total score was created by summing the mean scores of the 6 primary care domains. Though the PCAT also gathers information on coordination of care, we elected not to include this domain in our analyses because it is limited to those who had a specialist visit $(n=135)$.

Covariates. We controlled for self-reported socioeconomic status, such as family income (less than $\$ 36,000$ a year vs more than $\$ 36,000$ a year), maternal employment (employed vs unemployed), and maternal education (less than high school vs education beyond high school); characteristics of the health care system, such as provider specialty (pediatrician vs family practice) and copayments for services (any vs none); and demographics (child aged less than 9-11 years vs 5-8 years), sex, health status (excellent or very good vs good, fair or poor) and insurance coverage (public coverage, private coverage, and uninsured). Covariates were selected from a conceptual model linking raceethnicity to disparities. ${ }^{24}$

\section{Analysis}

With small numbers of concordant relationships for some subgroups of children, it was necessary to assure sufficient power to determine the adequacy of the subsamples to detect anticipated effect sizes. Overall, there was sufficient power in each of the subsamples (with the exception of the African American subsample) to detect meaningful differences in primary care scores, in some cases as small as 8 points. A full discussion of power of the sample is available in Appendix A on the online version at www.annfammed.org/ cgi/content/full/1/2/105/DC1.

The generalized linear model (GLM) procedure was used to assess differences in primary care experience scores for children in concordant and discordant relationships. Bivariate analyses were run for the total sample, for minorities (combining African Americans, Asian and Pacific Islanders, and Latinos), and for each racial and ethnic group separately. We repeated the analysis adjusting for the study covariates that were at least moderately correlated with primary care $(P<.10)$, including health status, insurance coverage and type, family income, and pediatrician specialty.

The GLM procedure was also used to compare primary care experiences across racial and ethnic groups to determine whether having a racially and ethnically concordant relationship would help eliminate known disparities in primary care experiences. ${ }^{1-8}$ We examined disparities in primary care among those with concordant relationships and then among discordant groups. If race/ethnicity concordance would reduce disparities in primary care, we hypothesized that the size of disparities between minority groups and whites would be smaller in concordant relationships than for those in discordant groups.

Given the potential for both the geographic clustering of children within schools and the possibility that 
parents might learn of health care providers from parents of their child's classmates, we examined whether the data were clustered by schools. Adjusting for clustering in the total sample made a negligible difference in the estimates and standard errors, so we did not make this adjustment.

\section{RESULTS}

Interviews were completed with the families of 413 children. Fifty-five children did not have a regular provider and were dropped from the analysis, resulting in a final analytic sample of 358 respondents. Subtracting unreachable families from the original sampling frame of 1,200 children (289 families had moved out of the school district, and 59 Asian-Pacific Islander families were unable to participate because of English language difficulty), the overall response rate was $48.5 \%$. Comparison of the respondents with the nonrespondents suggests that they were similar on most factors, except that respondents were slightly more likely than nonrespondents $(P<.05)$ to have a younger child (mean age 8.1 vs 8.4 years). Ninetyeight percent of respondents were mothers.

Table 1. Characteristics of the Sample by PatientProvider Racial and Ethnic Concordance ( $\mathrm{N}=358$ )

\begin{tabular}{|c|c|c|}
\hline Variable & $\begin{array}{l}\text { Percent in } \\
\text { Concordant } \\
\text { Relationship } \\
n=106\end{array}$ & $\begin{array}{c}\text { Percent in } \\
\text { Discordant } \\
\text { Relationship } \\
\mathbf{n}=252\end{array}$ \\
\hline \multicolumn{3}{|l|}{ Race and ethnicity } \\
\hline African American* & 5.7 & 34.9 \\
\hline Asian and Pacific Islander ${ }^{*}$ & 56.6 & 11.1 \\
\hline Latino* $^{*}$ & 11.3 & 28.6 \\
\hline White & 26.4 & 25.4 \\
\hline \multicolumn{3}{|l|}{ Demographics } \\
\hline Age $9-11$ years (vs $5-8$ years) & 42.5 & 44.1 \\
\hline Female & 51.9 & 44.8 \\
\hline $\begin{array}{l}\text { Excellent, very good health } \\
\text { (vs good, fair, poor) }\end{array}$ & 84.0 & 81.8 \\
\hline Public insurance coverage & 7.6 & 10.7 \\
\hline Uninsured & 4.7 & 7.1 \\
\hline \multicolumn{3}{|l|}{ Socioeconomic status } \\
\hline Family Income (> $\$ 36,000)$ & 82.1 & 75.8 \\
\hline Employment (employed) & 61.3 & 67.9 \\
\hline Education (> high school) ${ }^{\dagger}$ & 84.9 & 69.8 \\
\hline \multicolumn{3}{|l|}{ Health system factors } \\
\hline Pediatrician (vs family practice) & 41.5 & 38.9 \\
\hline Co-payments (vs none) & 77.4 & 71.0 \\
\hline \multicolumn{3}{|c|}{$\begin{array}{l}\text { Note: Percentages do not sum to } 100 \% \text { across rows, because they are the per- } \\
\text { centage of persons in concordant or discordant relationships with the particular } \\
\text { characteristic. }\end{array}$} \\
\hline \multicolumn{3}{|c|}{${ }^{*} \mathrm{P}<.001$ for the difference across concordant and discordant relationships. } \\
\hline \multicolumn{3}{|c|}{$\dagger \mathrm{P}<.01$ for the difference across concordant and discordant relationships. } \\
\hline
\end{tabular}

Table 1 shows the characteristics of the study sample for those in concordant and discordant relationships. There were few differences in demographic, socioeconomic status, and health system characteristics between the 2 groups. Overall, about $30 \%$ of respondents had a concordant relationship, though the percentage was lower for African Americans and Latinos. Maternal education was higher for children in concordant relationships ( $84.9 \%$ vs $69.8 \%$ completing high school) but is attributable to the larger number of whites and Asians (with higher educational levels) in concordant relationships.

\section{Unadjusted Primary Care Scores by Racial and Ethnic Concordance}

Table 2 shows the unadjusted primary care experience scores according to the concordance of the patientprovider relationship. For each racial and ethnic group, there was no significant association of concordance with parent reported experiences with care. One significant finding was a 14.6-point higher utilization score for whites in concordant relationships $(P<.05)$. In the combined minority analysis, there were no significant effects of concordance on primary care.

\section{Unadjusted Primary Care Scores by Racial and Ethnic Group}

In Table 2 we can also examine whether concordant relationships reduced disparities in primary care experience across racial and ethnic groups. The table shows that among those with concordant relationships, minorities experienced lower primary care scores than whites in 4 of 6 domains, including the total score. The utilization domain, in particular, was more than 20\% lower for minorities in concordant relationships than for whites $(65.1$ vs $85.7, P<.01)$. Parents of Asian children in concordant relationships also reported lower comprehensiveness of services available (78.6 vs $88.1, P<.01)$ and overall primary care scores $(75.3$ vs $84.1, P<.01)$ compared with whites. The results were similar within discordant relationships.

\section{Adjusted Primary Care Scores by Racial and Ethnic Concordance}

Table 3 shows primary care experience scores by racial and ethnic concordance adjusted for child health status, health insurance coverage and type, family income, and pediatric specialty. The difference in primary care utilization scores between concordant and discordant relationships for whites became nonsignificant. The adjusted minority and total sample analyses continue to show almost no effects of racial and ethnic concordance. 
Table 2. Bivariate Patient-Provider Racial Concordance and Primary Care Experience by the Total Sample, Minority Status, and Racial and Ethnic Groups Separately ( $=358)$.

\begin{tabular}{|c|c|c|c|}
\hline $\begin{array}{l}\text { Primary Care } \\
\text { Experience }\end{array}$ & $\begin{array}{l}\text { Concordant } \\
\text { Mean (SD) }\end{array}$ & $\begin{array}{l}\text { Discordant } \\
\text { Mean (SD) }\end{array}$ & $\Delta$ \\
\hline Total $(n=358)$ & $n=106$ & $n=252$ & \\
\hline Accessibility & $71.2(12.4)$ & $73.6(12.4)$ & -2.4 \\
\hline Utilization & $70.5(35.0)$ & $64.5(36.2)$ & 6.0 \\
\hline Relationship & $88.0(21.9)$ & $83.9(24.1)$ & 4.1 \\
\hline Services available & $85.9(10.8)$ & $86.2(10.9)$ & -0.3 \\
\hline Services received & $82.5(13.4)$ & $83.8(12.4)$ & -1.3 \\
\hline Total score & $70.7(23.5)$ & $70.0(25.0)$ & 0.7 \\
\hline Minority $(n=266)$ & $n=78$ & $\mathrm{n}=188$ & \\
\hline Accessibility & $70.9(12.4)$ & $73.4(12.5)$ & -2.5 \\
\hline Utilization & $65.1(36.1)^{*}$ & $62.2(36.7)$ & 2.9 \\
\hline Relationship & $86.5(22.3)$ & $81.8(25.1)^{*}$ & 5.3 \\
\hline Services available & $85.1(10.6)$ & $84.9(11.1)^{\dagger}$ & 0.2 \\
\hline Services received & $80.6(14.5)^{*}$ & $83.2(12.7)$ & -2.6 \\
\hline Total score & $67.9(24.3)^{\dagger}$ & $68.8(25.4)$ & -0.9 \\
\hline $\begin{array}{l}\text { Asian and Pacific } \\
\text { Islander }(\mathrm{n}=88)\end{array}$ & $n=60$ & $n=28$ & \\
\hline Accessibility & $69.7(12.9)$ & $71.5(13.6)$ & -1.8 \\
\hline Utilization & $65.8(34.7)$ & $57.1(35.3)$ & 8.7 \\
\hline Relationship & $87.9(21.3)$ & $81.3(24.2)$ & 6.6 \\
\hline Services available & $84.6(11.0)$ & $84.5(10.2)$ & 0.1 \\
\hline Services received & $78.6(14.6)^{*}$ & $77.7(16.2)^{\dagger}$ & 0.9 \\
\hline Total score & $65.4(24.5)$ & $67.9(27.0)$ & -2.5 \\
\hline $\begin{array}{l}\text { African American } \\
(\mathrm{n}=94)\end{array}$ & $\mathrm{n}=6$ & $\mathrm{n}=88$ & \\
\hline Accessibility & $77.1(5.5)$ & $74.5(12.4)$ & 2.6 \\
\hline Utilization & $62.5(37.9)$ & $61.1(37.3)$ & 1.4 \\
\hline Relationship & $91.7(20.4)$ & $82.6(24.4)$ & 9.1 \\
\hline Services available & $85.1(13.3)$ & $84.9(10.5)^{\dagger}$ & 0.2 \\
\hline Services received & $92.0(8.8)$ & $84.9(11.7)$ & 7.1 \\
\hline Total score & $79.2(28.7)$ & $67.5(26.2)$ & 11.7 \\
\hline Latino $(n=84)$ & $\mathrm{n}=12$ & $n=72$ & \\
\hline Accessibility & $73.8(11.6)$ & $72.7(12.1)$ & 1.1 \\
\hline Utilization & $62.5(44.6)$ & $65.6(36.7)$ & -3.1 \\
\hline Relationship & $77.1(27.1)$ & $80.6(26.6)$ & -3.5 \\
\hline Services available & $87.2(7.6)$ & $85.2(12.1)$ & 2.0 \\
\hline Services received & $84.7(13.5)$ & $83.2(12.0)$ & 1.5 \\
\hline Total score & $75.0(19.2)$ & $70.8(24.1)$ & 4.2 \\
\hline White $(n=92)$ & $n=28$ & $n=64$ & \\
\hline Accessibility & $72.3(12.4)$ & $74.2(12.3)$ & 1.9 \\
\hline Utilization & $85.7(26.7)$ & $71.1(34.0)$ & $14.6^{\ddagger}$ \\
\hline Relationship & $92.0(20.5)$ & $90.2(19.7)$ & 1.8 \\
\hline Services available & $88.3(11.2)$ & $90.0(9.8)$ & -1.7 \\
\hline Services received & $88.1(7.8)$ & $85.4(11.4)$ & 2.7 \\
\hline Total score & $78.4(19.8)$ & $73.6(23.6)$ & 4.8 \\
\hline \multicolumn{4}{|c|}{$\begin{array}{l}\text { * } P<.01 \text { for the difference in mean score for each racial or ethnic group compared to white across concor- } \\
\text { dant and then discordant groups (eg, comparing accessibility scores for Asians in concordant relationships } \\
\text { with whites in concordant relationships). }\end{array}$} \\
\hline \multicolumn{4}{|c|}{$\begin{array}{l}\text { †P<.05 for the difference in mean score for each racial or ethnic group compared to white across concor- } \\
\text { dant and then discordant groups (eg, comparing accessibility scores for Asians in concordant relationships } \\
\text { with whites in concordant relationships). }\end{array}$} \\
\hline \multicolumn{4}{|c|}{$\begin{array}{l}\ddagger P<.05 \text { for the difference between racially concordant and discordant patient-provider relationships, within } \\
\text { each racial and ethnic group. }\end{array}$} \\
\hline
\end{tabular}

Adjusted Primary Care Scores by Racial and Ethnic Group

Table 3 also examines whether concordant relationships reduced disparities in primary care experience across racial and ethnic groups. Minorities continue to experience disparities in the utilization domain among those in concordant relationships compared with whites $(65.0$ vs $84.8, P<.01)$ and for the primary care total score $(76.0$ vs 83.9, $P<.05)$. The trend for lower utilization among racial and ethnic subgroups remained consistent across subgroups. Asian children in concordant relationships continued to have lower comprehensiveness of services received scores than whites $(78.4$ vs $88.7, P<.01)$. The results were similar within discordant relationships.

\section{DISCUSSION}

The findings of our study suggest that while there are some striking racial and ethnic disparities in primary care experiences, there is little evidence of an association between patient-provider race/ethnicity concordance and parent-reported primary care experiences of children. Moreover, having a concordant relationship did not reduce disparities in primary care experiences between minorities and whites. This finding raises questions about whether discordant patient-provider relationships contribute to disparities.

Because previous research among adults has shown some benefits of race/ethnicity concordance, there might be several possible explanations for our novel findings. First, perceptions or stereotypes that contribute to disparities among adult patients might be attenuated in relationships involving children. For example, providers might not have the same biases or assumptions about children and families as when caring for adults.

A substantial body of literature 
Table 3. Adjusted Patient-Provider Racial Concordance and Primary Care Experience by the Total Sample, Minority Status, and Racial and Ethnic Groups Separately ( $\mathrm{N}=358$ ).

\section{Primary Care \\ Experience}

Total $(\mathbf{n}=358)$

Accessibility

Utilization

Affiliation

Relationship

Services available

Services received

Total score

Minority $(n=266)$

Accessibility

Utilization

Affiliation

Relationship

Services available

Services received

Total score

Asian and Pacific

Islander $(\mathrm{n}=\mathbf{8 8})$

Accessibility

Utilization

Affiliation

Relationship

Services available

Services received

Total score

African American ( $n=94)$

Accessibility

Utilization

Affiliation

Relationship

Services available

Services received

Total score

Latino $(n=84)$

Accessibility

Utilization

Affiliation

Relationship

Services available

Services received

Total score

White $(\mathrm{n}=92)$

Accessibility

Utilization

Affiliation

Relationship

Services available

Services received

Total score

\section{Concordant \\ Mean (SD)}

$\mathrm{n}=106$

$71.2(1.2)$

$70.2(3.4)$

$87.7(2.3)$

$85.9(1.0)$

$82.4(1.2)$

$70.5(2.3)$

$78.0(1.2)$

$\mathrm{n}=78$

$70.9(1.4)$

$65.0(4.1)$

$86.4(2.8)$

$85.1(1.2)$

$80.5(1.5)$

$68.1(2.8)$

$76.0(1.4)^{\dagger}$

$\mathrm{n}=60$

$69.5(1.7)$

$66.2(4.6)$

$87.8(2.9)$

$84.7(1.3)$

$78.4(1.9)^{*}$

$64.8(3.2)$

$75.2(1.6)$

$\mathrm{n}=6$

$76.3(5.0)$

$61.3(15.3)$

$91.2(9.9)$

$84.2(4.4)$

$91.6(4.6)$

74.7 (10.6)

$79.9(5.1)$

$\mathrm{n}=12$

$74.4(3.7)$

$66.9(10.7)$

$77.5(8.0)$

$89.8(3.2)$

$86.7(3.7)$

$80.2(6.7)$

76.0 (1.4)

$\mathrm{n}=28$

72.7 (2.3)

$84.8(6.2)$

$91.2(3.8)$

$88.3(1.8)$

$88.7(2.0)$

$77.9(4.3)$

$83.9(2.2)$

\section{Discordant}

Mean (SD)

$\Delta$

$\mathrm{n}=252$

$73.5(0.8)$

$64.6(2.2)$

$84.0(1.5)$

$86.3(0.7)$

$83.8(0.8)$

$70.1(1.5)$

$77.1(0.8)$

$\mathrm{n}=188$

$73.3(0.9)$

$62.2(2.6)$

$81.8(1.8)^{\dagger}$

$84.9(0.8)^{*}$

$83.2(1.0)$

$68.7(1.8)$

$75.7(0.9)^{*}$

$\mathrm{n}=28$

$71.9(2.5)$

$56.3(6.7)$

$81.6(4.3)$

$84.4(1.9)^{\dagger}$

$78.0(2.8)^{\dagger}$

$69.2(4.7)$

73.6 (2.4)

$\mathrm{n}=88$

$74.6(1.3)$

$61.1(4.0)$

$83.0(2.6)$

$84.9(1.1)$

$84.9(1.2)$

$67.8(2.7)$

76.1 (1.3)

$\mathrm{n}=72$

$72.6(1.4)$

64.9 (4.2)

$80.5(3.1)$

$84.8(1.3)$

$82.9(1.4)$

$70.0(2.6)$

$75.7(0.9)$

$\mathrm{n}=64$

$74.0(1.5)$

71.5 (4.0)

$90.6(2.5)$

$90.0(1.2)$

$85.2(1.3)$

$73.8(2.8)$

80.9 (1.4) has described several potential pathways by which provider biases or stereotypes might influence health care experiences for adults. Provider perceptions or assumptions regarding social or cultural norms might unintentionally affect interactions with patients.

Providers might intentionally tailor their interpersonal behaviors or service delivery to address cultural differences in patient expectations for care. Intentional and unintentional provider behaviors and treatment decisions might be affected by social or cultural stereo-

types. ${ }^{25,26}$ Whereas these pathways have been found among adults, such processes might not occur in health care involving children.

Second, for Asian-Pacific

Islanders and Latinos, the potential benefits of patient-provider racial and ethnic concordance might derive primarily from overcoming language barriers. Because our study included nearly all English-speaking respondents, the children and families in our sample might not need to derive the same benefits from concordance as non-English speaking families. This possibility, however, does not explain the lack of effect of concordance for African-Americans. Similarly, race/ethnicity concordance might play a greater role for younger and older children (less than 5 years of age, and older than 12 years of age) who were not included in our study and who generally visit physicians more frequently.

Third, previous studies showing an effect of race/ethnicity concordance have focused primarily on subjective ratings of communication and satisfaction that are more likely to be affected by racial and ethnic differences in perceptions and expectations for care. The primary care measure used in this study relied primarily on parent reports of experiences against a prescriptive criterion rather than subjective ratings, and thus might be less subject dant and then discordant groups (eg, comparing accessibility scores for Asians in concordant relationships with whites in concordant relationships).

$+P<.05$ for the difference in mean score for each racial or ethnic group compared to white across concordant and then discordant groups (eg, comparing accessibility scores for Asians in concordant relationships with whites in concordant relationships). 
to preferences for racially and ethnically concordant providers reported in other work. ${ }^{27}$

This study has several limitations. First, no instrument has yet been developed to assess reliably the primary care experiences from the child's perspective. Studies of race/ethnicity concordance and primary care experience might, however, benefit from the measurement of interpersonal factors from the child's perspective. In assessing primary care for their children, parents might incorporate experiences with their own health care, rather than just the experiences involved in obtaining care for their children. Moreover, parents might not be the same race or ethnicity as their child, and because we measured concordance of the child and provider, the effects of concordance could have been weakened.

Second, very few African American and Latino respondents had concordant relationships, limiting the power of the sample to detect adequately small differences in primary care experience for these groups. For most analyses, there was sufficient power to detect differences of 10 to 12 points or more (our anticipated effect sizes), though for some subgroups there was additional power to detect 8-point differences or even less. There were also relatively small sample sizes with regard to the insurance variables for concordant groups that suggest additional caution in drawing inferences from Table 3.

We addressed potential concerns about inadequate power by conducting minority and total sample analyses as a validity check for the subgroup analyses. Because the benefits of concordance would be likely to accrue through similar mechanisms for the racial and ethnic subgroups (eg, cultural factors, trust and rapport, provider biases, and communication factors), subsequently combining the groups provides greater power for looking at the effects of race and ethnicity concordance without forfeiting the concept that minority groups have unique health care needs and experiences.

Disparities in the number of minority health care providers made it difficult to find adequate numbers of African American and Latino children with concordant patient-provider relationships in community-based studies. ${ }^{28,29}$ One recent study showed that less than $6 \%$ of all current medical students were African American, and only about $5 \%$ were Latino, making race concordant relationships for these groups both difficult to establish in practice and find in research. ${ }^{30}$ Alternate study designs, such as case-control or randomizedcontrolled studies, might better select for concordant relationships.

We examined 4 broad classifications of race and ethnicity and were not able to capture subgroup variations in ethnicity (of children and providers). The study measures, therefore, might not capture all cultural, socioeconomic status, political, and historical aspects of multiculturalism that would likely produce more complex findings than are reported here. ${ }^{31,32}$ Third, few interviews were conducted in Spanish, and non-English speaking Asian and Pacific Islanders were not interviewed, which did not allow us to account for potential linguistic benefits of racial and ethnic concordance. On the other hand, we were able to indirectly examine nonlinguistic mechanisms of race/ethnicity concordance (eg, cultural competence and provider biases) that have been hypothesized to influence health care experiences.

Despite these limitations, this study offers the first data on the association between patient-provider racial and ethnic concordance and parent-reported health care experiences of children. The study uniquely examines the effects within a community-sample of children to avoid biases associated with clinic-based samples that capture only the most frequent users of services. In addition, using a well-validated and reliable measure of primary care experiences that relies more on reporting than rating provides a view of disparities in care that is less influenced by racial and ethnic variations in patient expectations, and provides a more stable foundation for changing physician practice or health policy.

Given a national health policy priority of reducing racial and ethnic disparities in health and increasing cultural competence among providers, it is surprising that there are currently no ongoing national surveys that collect information on patient-provider racial and ethnic concordance for children. Research on concordance, particularly when using more objective measures of the content or quality of care, might help to assess provider contributions to eliminating disparities in health care. Current evidence on concordance is conflicting and requires more highly powered studies. Collection of provider race and ethnicity data, therefore, might be considered for incorporation into national surveys of health care quality and experiences, such as the Consumer Assessment of Health Plans Survey (CAHPS) or the Medical Expenditure Panel Survey (MEPS).

In conclusion, this study suggests that patientprovider race/ethnicity concordance might not help eliminate racial and ethnic disparities in primary care for children. With so much political attention given to eliminating racial and ethnic disparities in health and health care, these findings are uniquely provocative in that they raise questions about whether discordant relationships contribute to disparities in care. Future studies should further attempt to explore the underlying mechanisms of disparities in health care by includ- 
ing racial and ethnic subgroups in analyses, accounting for language concordance between patients and providers, and consider children's perspectives in evaluating interpersonal aspects of care.

To read commentaries or to post a response to this article, see the online version at http://annfammed/cgi/content/full/1/2/105.

Key words: Physician-Patient Relations, Ethnic Groups, Delivery of Health Care/in infancy and childhood, Primary Care

Submitted February 27, 2003; accepted March 13, 2003.

\section{Acknowledgment}

Dr. Cooper is supported by a grant from the Commonwealth Fund. The views presented here are those of the authors and not necessarily those of the Commonwealth fund, its directors, officers, or staff.

\section{References}

1. Stevens G, Shi L. Racial and ethnic disparities in the primary care experiences of children: a review of the literature. Med Care Res Rev 2002;60:3-30

2. Weech-Maldonado R, Morales L, Spritzer K, Elliot M, Hays R. Racial and ethnic differences in parents' assessments of pediatric care in Medicaid managed care. Health Serv Res 2001;36(3):575-594.

3. Flores $G$, Bauchner $H$, Feinstein AR, Nguyen $U$. The impact of ethnicity, family income, and parental education on children's health and use of health services. Am J Public Health 1999;89(7):10661071.

4. Newacheck PW, Hughes DC, Stoddard J. Children's access to primary care: differences by race, income and insurance status. Pediatrics 1996;97(1):26-32

5. Lieu TA, Newacheck PW, McManus MA. Race, ethnicity, and access to ambulatory care among U.S. adolescents. Am J Public Health 1993;83(7):960-965.

6. Weinick R, Krauss N. Racial and ethnic differences in children's access to care. Am J Public Health 2000;90(11):1771-1774.

7. Weitzman M, Byrd RS, Auinger P. Black and white middle class children who have private health insurance in the United States. Pediatrics 1999;104(1 Pt. 2):151-157.

8. Halfon N, Inkelas M, Wood D. Nonfinancial barriers to care for children and youth. Annu Rev Public Health 1995;16:447-472.

9. Smedley B, Stith A, Nelson A, eds. Unequal Treatment: Confronting Racial and Ethnic Disparities in Health Care. Washington, DC: National Academy Press; 2003.

10. Collins K, Hughes D, Doty M, Ives B, Edwards J, Tenney K. Diverse Communities, Common Concerns: Assessing Health Care Quality For Minority Americans. New York, NY: The Commonwealth Fund; 2002:523.

11. Cooper-Patrick L, Gallo J, Gonzales J, et al. Race, gender, and partnership in the patient-physician relationship. JAMA 1999;282(6): 583-589.
12. Saha S, Komaromy M, Koepsell T, Bindman A. Patient-physician racial concordance and the perceived quality and use of health care. Arch Intern Med 1999;159(9):997-1004.

13. Fergusen W, Candib L. Culture, language, and the doctor-patient relationship. Fam Med 2002;34(5):353-361.

14. Malat J. Social distance and patients' rating of healthcare providers. J Health Soc Behav 2001;42(4):360-372.

15. Forrest C, Simpson L, Clancy C. Child health services research. Challenges and opportunities. JAMA 1997;277:1787-1793.

16. Fuchs $S$, Guimaraes $S$, Sortica $C$, et al. Reliability of race assessment based on the race of the ascendants: a cross-sectional study. BMC Public Health 2002;2(1).

17. Donaldson M, Yordy K, Lohr K, Vanselow N. Primary Care: America's Health in a New Era. Washington, DC: National Academy Press; 1996.

18. Starfield B. Primary Care: Balancing Health Needs, Services, and Technology. New York, NY: Oxford University Press; 1998.

19. Primary Care Assessment Tool - Child Edition (PCAT-CE). Baltimore, Md: Primary Care Policy Center for the Underserved, Johns Hopkins University School of Hygiene and Public Health, 1998.

20. Starfield B, Cassady C, Nanda J, Forrest CB, Berk R. Consumer experiences and provider perceptions of the quality of primary care: implications for managed care. The J Fam Pract 1998;46(3):216-226.

21. Darby C. Patient/parent assessment of the quality of care. Ambul Pediatr 2002;2(4 Suppl):345-348.

22. Cassady C, Starfield B, Hurtado M, Berk R, Nanda J, Friedenberg L. Measuring consumer experiences with primary care. Pediatrics 2000 105(4 Pt 2):998-1003.

23. Shi L, Starfield B, Xu J. Validating the Adult Primary Care Assessment Tool. J Fam Pract 2001;50(2):E1.

24. Stevens G, Shi L. Racial and ethnic disparities in the quality of primary care for children. J Fam Pract 2002;51(6):573.

25. van Ryn M. Research on the provider contribution to race/ethnicity disparities in medical care. Med Care 2002;40(1 Suppl):140-151.

26. van Ryn M, Burke J. The effect of patient race and socio-economic status on physicians' perceptions of patients. Soc Sci Med 2000;50: 813-828.

27. Saha S, Taggart S, Komaromy M, Bindman A. Do patients choose physicians of their own race? Health Aff (Millwood) 2000;19(4):76-83.

28. Stoddard J, Back M, Brotherton S. The respective racial and ethnic diversity of US pediatricians and American children. Pediatrics 2000; 105(1 Pt 1):27-31.

29. Cohen J, Gabriel B, Terrell C. The case for diversity in the health care workforce. Health Aff (Millwood) 2002;21(5):90-102.

30. Brotherton S, Simon F, Etzel S. US graduate medical education, 2001-2002: changing dynamics. JAMA 2002;288(9):1073-1078.

31. Schulman K, Rubenstein L, Chesley F, Eisenberg J. The roles of race and socioeconomic factors in health services research. Health Serv Res 1995;30(1 Part 2):179-195.

32. LaVeist T. Beyond dummy variables and sample selection: what health services researchers ought to know about race as a variable. Health Serv Res 1994;29(1):1-16. 